\title{
2021 Miles Conrad Award Lecture: Heather Joseph
}

\author{
Heather Joseph* \\ Executive Director, Scholarly Publishing and Academic Resources Coalition (SPARC), Washington, \\ $D C, U S A$
}

\begin{abstract}
This paper is based upon the 2021 Miles Conrad Award Lecture that was given by Heather Joseph at the second annual NISO Plus conference held virtually from February 22-25, 2021. The lecture provided a brief look back at the emergence of the Open Access (OA) movement in scholarly communication beginning with the E-biomed proposal in 1999 that was shortly followed by the Budapest Declaration released on February 14, 2002, through how far it has come in almost two decades. The author notes that the initial reaction to OA was often just a quick dismissal of it as an idealistic pipe dream and as the idea began to grow in popularity, skepticism changed into hostility. OA was criticized as being too disruptive to the then-existent publishing paradigm. Yet, far from disappearing, the movement towards the open sharing of knowledge steadily advanced. Today conversations about "why" or "whether" to open up the scholarly communication system have evolved into conversations about how best to do it.

The author notes that the Budapest Declaration underscored that the end goal of OA is to empower individuals and communities around the world with the ability to share their knowledge as well as to share in accessing the knowledge of others. She warns that members of the global scholarly communication community must look critically at who currently can participate in the production of knowledge, and whose voices are represented in the "global intellectual conversation" that need to be facilitated. Whose voices are still are left out because structural barriers - be they technical, financial, legal, cultural, or linguistic - prevent them from joining?
\end{abstract}

Keywords: Open access, scholarly communication, Miles Conrad Lecture 2021, SPARC, E-biomed, Budapest Declaration, social justice

\section{Introduction}

I want to thank the NISO Board of Directors for selecting me to receive the Miles Conrad Award - it is truly an honor. It is also daunting to think about reflecting on a "lifetime" of work, particularly because it feels like there is still so much more left to do. I've spent the bulk of my thirty-two-year professional career working on scholarly communication - specifically focused on trying to advance a system of sharing knowledge that is both open by default and equitable by design - a system where everyone, everywhere can contribute to and benefit from the free exchange of knowledge.

I'd like to share with you why improving openness and equity in this system has been such a central focus for me and the community I am privileged to serve, and to take an honest look at both how far we've come towards achieving the vision we share, and also how far we still have left to go.

\footnotetext{
*E-mail: heather@sparcopen.org.
} 


\section{Background}

Over my career, I've worked as a managing editor, a publisher, an online product lead, a policy developer, and an executive director. But at its heart, all the work that I do have done and continue to do is advocacy work. It is work that is geared towards creating systems-level change, and it is also work that is firmly rooted in a social justice context.

"There is social justice when everyone enjoys all human rights."

- Thuli Madonsela

One of the last in-person meetings I participated before the pandemic shutdown was a pan-African symposium on open access to knowledge in December of 2019, and the opening keynote was Thuli Madonsela, a South African advocate and law professor, who helped draft South Africa's current constitution. She opened the meeting by contextualizing the importance of open access to knowledge in a social justice framing. She reminded us that day that social justice movements often have widelyvarying focuses - they may be centered on gender equality or civil rights or anti-globalization, or any of a host of things - but they all share the commonality that they are firmly rooted in the way in which human rights are manifested in the everyday lives of people at every level of society.

This is a critical ideal for us to keep in mind - because sharing knowledge is a fundamental human right. It is enshrined as such in the United Nation's Universal Declaration of Human Rights [1] where Article 27, states that everyone has the right freely to participate in the cultural life of the community, to enjoy the arts and, in particular, to share in scientific advancement and its benefits.

The centrality of this right is also reflected in the UN's 2030 Sustainable Development Goals (SDGs) [2], which serve as the organization's current blueprint and action plan to ensure a better future for all citizens of the world. Ensuring equitable access to knowledge is a specific target in Goal 16, which calls for building effective, accountable, and inclusive institutions, and ensuring public access to information.

However, the UN has also recognized that this is also a cross-cutting issue that has the potential to accelerate progress towards meeting all the SDG's which are almost universally dependent on the free flow of information and knowledge among communities and across geographic borders to succeed.

These are large scale goals. They underscore that the changes that are needed to improve the way in which we share knowledge must take place on a global systems level and be firmly rooted in social justice. To be truly effective, our strategies/solutions for improving the knowledge sharing system also must comprehensively address all the primary social justice principles: access, participation equity, and rights.

Ultimately, achieving these goals is what drives me. But I want to point out that I didn't start out with this explicit vision and framing front of my mind. It's grown and come into focus over the arc of my career. I was extremely fortunate to have had the chance to work for and with some incredibly smart, visionary, and generous people who gave me incredible foundational opportunities from the day I started working in this arena.

\section{Career history and lessons learned}

My first job in scholarly communications was with the American Astronomical Society (AAS) in 1989, where I started out as Publications Manager. The Executive Director, Peter Boyce, played a huge role in 
influencing how I approach the challenge of communicating science and scholarship. I started my job at the very moment that the idea of using digital networked technology to share science was beginning to emerge.

I clearly remember Peter excitedly telling the AAS team about the promise of large-scale computer networks and giving us all our first email accounts - they were BITNET addresses. He pointed out that AAS member scientists were already collecting data largely through digital technologies and sharing it with each other in the same way. He commented that it was only a matter of time before they would turn to us as the organization designed to help support the promotion and communication of astronomy and astrophysics and say "hey - we're doing all of this work online, but when we want to submit an abstract for talk or a poster, or an article for one of the journals, we have to stop, go offline and put it on paper. This is a bottleneck. You all need to figure how to meet us where we are working...."

The thing is, Peter didn't view this as a problem to be worried about - he was genuinely excited about it. He viewed this emerging technology as an opportunity for us to rise to the challenge. He shared that enthusiasm with us as a team and empowered us all - including those of us literally just starting out on our own professional paths - to contribute.

Peter would toss us into the deep end and trust that we would be able to float. He wasn't cavalier about it; he was always there to provide insight, support, and the resources we needed to help us learn. But he trusted us to think for ourselves, and to bring our own unique perspectives to the table to suss out solutions. He encouraged me (a non-scientist who had never written a journal article) to look at how our scientists were composing their abstracts and papers - using LaTeX [3], because it could represent the complex mathematical equations so prevalent in that discipline.

I'd never used it before, so I went to TeX [4] users' group meetings, became part of the American Institute of Physics (AIP) TeX Working Group, and spent hours and hours with our publishing partners at AIP and the University of Chicago Press working to unpack the article composition and submission process. While I never truly mastered writing in LaTeX, I learned enough to understand its critical role in the workflow of communicating science. I learned it just in time, because, of course, at exactly that time, the World Wide Web was just about to emerge from the European Organization for Nuclear Research (CERN).

Once it did, we knew that this was the missing link in the creation of an end-to-end digital workflow for our members. So, finding a way to take LaTeX and represent it in a format that could take advantage of this emerging platform became the first major professional project I worked on, along with Peter, and a wonderful team of people from our publishing partners, the U.S. National Aeronautics and Space Administration (NASA), and the astronomical library community.

We focused on finding a way to convert LaTeX to a language that could not only be displayed on the Web, but also take make the content easily identifiable and searchable at granular level. This pointed directly to structured markup language, and at the time, SGML was the language we used. As a team, we presented our idea to the National Science Board, received a grant from the National Science Foundation (NSF) and even though I was still a twenty-something newbie, I served as Co-Principal Investigator on the grant, and we were off to the races. It was some of the hardest work I've ever done, but also some of the most rewarding and the most fun.

We ultimately delivered a successful prototype of one of our flagship journals - the Astrophysical Journal Letters. And just as critically, my entire world view of scientific communications was shaped by my time there. Working for the AAS on that project taught me that: 
(1) Scientific communication was improved and accelerated by how we use consistently evolving technology to help the researcher community communicate science how and when they wanted, and in the formats and over channels that worked best for them.

(2) The Internet creates massive opportunities to be explored and leveraged to do this better.

(3) What we are communicating is information - the building blocks of knowledge - and that the ultimate packaging should be as flexible and fluid as possible.

Because I didn't grow up as a scientist or as a journal user, I wasn't trained to think of journals and articles as things that were somehow sacrosanct or not subject to change. Because my first job was this deep dive into essentially deconstructing both of these structures, I have always approached them with the mindset that they are just structured data, and that the data could just as easily be structured differently if the current packaging was not serving the scientific community's needs. Most importantly, it wasn't up to me to say what the channel or package should ultimately look like - it was up to the community.

This grounding served me well. Particularly when I left the physical sciences and went to work for the American Society for Cell Biology (ASCB) where I had an experience that added another critical dimension to my approach to scientific and scholarly communication.

\section{Emergence of the Open Access (OA) movement}

In 1999, Harold Varmus, then the director of the National Institutes of Health (NIH), along with Pat Brown and David Lipman, proposed a radical new approach to scientific communications. They noted that even though some folks were making journals available electronically, the community still was not taking full advantage of the power of the intent to communicate science widely and without significant barriers.

They proposed establishing a new platform, E-biomed [5], hosted by the NIH, that would house all NIH-funded biomedical research outputs - from data to unreviewed papers to fully peer reviewed articles - and make then openly available to all. They proposed that authors (who would retain the full copyright to their work) should be able to submit works directly to the platform, where they could either be presented immediately to the community (as pre-preprints or move into a peer review stream that is run by an existing journal, or a subset of the community, etc. The proposal to open up immediate access to research outputs was quickly met by a firestorm of concern and criticism [6].

As a journal publisher at the time, my initial reaction was the same as many in the community. "Wellthis is going to blow up the whole current system - so there's ten years of my career down the tubes." But fortunately, the scientists who served as the lead Editors for the ASCB journals that I managed (David Botstein and Keith Yamamoto) were cut from the same cloth as Peter Boyce. Their first reaction was "hey - as scientists, we actually like the way this sounds. They encouraged us to work together to stop, think it though and, most importantly, to not be afraid to dig in and have as many conversations with the people proposing this new model as possible, to understand where they are trying to go - and then to see if there were things that we could do to contribute to it that would benefit our scientists once again. Their goal was to figure out how play a role in contributing to this evolution for the benefit of the scientific community not to fight against it.

While the vision of E-biomed as a portal for immediate free access to all NIH funded research outputs was ultimately pared down into a single database to provide faster access to peer-reviewed journal articles, PubMed Central (PMC) I am incredibly proud that we at the ASCB became the first publisher to commit 
the full content of our flagship journal, Molecular Biology of Cell to that pioneering database. And perhaps most importantly, my exposure to the E-biomed proposal was the first time that I learned about the ideas that would ultimately combine to define the movement that I would spend the next twenty years of my career advocating for - the movement towards providing Open Access to knowledge.

The E-biomed proposal contained the fundamental elements that came to define an open access knowledge environment: author-driven publishing on open platforms that are funder-subsidized, free to publish on, and free to access with authors retaining ownership of their intellectual output, and with peer review occurring where and when the community chooses. The Open Access movement brought all the pieces together for me: the lessons learned on the ground as a journal publisher, the ethos of scientific communication in service to the research community, and the opportunity to leverage the Internet as a communication channel that could radically improve - and democratize - the sharing of knowledge.

I was very fortunate to have just taken on a new role at SPARC (the Scholarly Publishing and Academic Resources Coalition) when in December 2001, the Open Society Institutes brought together stakeholders to re-envision using the Internet to optimize how knowledge could be shared globally. The result of that meeting (in which SPARC participated) was the launch of the Budapest Open Access Initiative and issuance of the Budapest Declaration on Open Access [7].

The Declaration was at once a statement of principle, a statement of strategy, and a commitment to action. It underscored the unique opportunity that the emergence of the Internet and, in particular, the World Wide Web, presented to re-imagine and optimize the way we share scientific and scholarly knowledge. The Declaration opened by noting:

"An old tradition and a new technology have converged to make possible an unprecedented public good.

The old tradition is the willingness of scientists and scholars to publish the fruits of their research in scholarly journals without payment, for the sake of inquiry and knowledge. The new technology is the Internet. The public good they make possible is the world-wide electronic distribution of the peer-reviewed journal literature, and completely free and unrestricted access to it by all [8]."

It provided the seminal definition of Open Access that remains in wide use today, explicitly calling for the establishment of knowledge-sharing norms that enable not only free immediate availability of scholarly articles, but also the full digital reuse of the information contained in them. The document posited that it wasn't enough for readers to be able to simply access individual PDF's of articles to read online, they needed to be ensured the right to read, download, copy, distribute, print, search, or link to the full texts of these articles, crawl them for indexing, pass them as data to software, or use them for any other lawful purpose, without financial, legal, or technical barriers other than those inseparable from gaining access to the Internet itself.

Ensuring this robust kind of productive reuse would allow the value of the information contained in digital articles to be fully unlocked, as the entire global corpus of scholarly knowledge would be available to text and data mine, and to readily apply new computational techniques such as Machine Learning and Artificial Intelligence, creating an unimaginable wealth of new discovery opportunities.

The Budapest Declaration was also careful to acknowledge the continued value of copyright, while also recognizing that its application should be done in ways that would significantly increase the impact of scientific and scholarly articles, rather than continue to limit it. The only constraint on reproduction and distribution, the Declaration argued, and the only role for copyright in this domain should be to give authors control over the integrity of their work and the right to be properly acknowledged and cited. This focus helped give rise to the wide-spread use of open licenses.

But of all the contributions that the Budapest Declaration made to changing the nature of scholarly communication, perhaps the most critical was that it centered the imperative of treating knowledge sharing 
as a social justice issue. It inherently recognized that access to knowledge is a fundamental human right and called for the open sharing of knowledge to achieve very specific, globally resonant goals.

"Removing access barriers will accelerate research, enrich education, share the learning of the rich with the poor and the poor with the rich, make this literature as useful as it can be, and lay the foundation for uniting humanity in a common intellectual conversation and quest for knowledge [9]."

This set us on the path to where we are today. The Budapest gathering was followed in short order by seminal meetings of research and funding communities in Bethesda, Berlin, and Salvador da Bahia that produced statements affirming the message of the Budapest Declaration and launched a global movement that quickly gained momentum.

\section{Open Access today}

And we have come so far. It's a far cry from the first years of the Open Access movement, when few people had heard of the concept, and the initial reaction was often just quick dismissal of it as an idealistic pipe dream. As the idea began to grow in popularity, skepticism changed into outright hostility, and Open Access was criticized as being too disruptive to the current publishing paradigm. We've spent two decades working through a host of opposing arguments that have ranged from claims that Open Access would undermine peer review to assertions that it would destroy copyright and intellectual property protections to dire predictions that it would drive scores of publishers out of business.

And yet, far from disappearing, the movement towards open sharing of knowledge has steadily advanced. We are no longer having conversations about "why" or "whether" to open up the scholarly communication system - but rather how best to do it. We can see the progress that has been made towards making open the default when we look at milestones such as:

- Open Access publishing has become the fastest growing segment of the scholarly market, with both commercial and non-for-profit publishers increasingly offering open publishing options [10].

- The growing set of open access repositories - and more importantly - the highly-functional networks of repositories (OpenAire, La Referencia, etc.) that are currently in use around the world.

- The United Nations has embraced open access, affirming the right to share knowledge as a human right, and explicitly recognizing open science and open access as an accelerator for their global mission of improving society for all. Similarly, UNESCO has proposed a set of strong recommendations for the global adoption of Open Access, expected to be ratified by its one hundred and ninety-three member countries in November of 2021 [11].

- Similarly, multinational organizations in the UN's system of related organizations (including the World Bank, the WHO, UNESCO and more) are also centering open access practices, opening access to critical data and publications, and using open as enabling strategy to achieve global Sustainable Development Goals.

- Policy makers have recognized the importance of Open Access as critical element of innovation and competitiveness agendas and are increasingly implementing strong Open Access polices. Globally, research funders have become leading advocates for open access and are actively organizing collaborative efforts to extend and amplify the uptake of Open Access through efforts including cOAlition S [12].

- Private funders - foundations and philanthropies- are acting in kind. The Open Research Funders Group (ORFG), which I am proud to note that SPARC founded and convenes, is a group of twenty-one private 
foundations and philanthropies who hold combines assets in excess of $\$ 250$ billion, with a total research investment of over $\$ 12$ billion annually, and who are leading the way in individually and collectively promoting Open Access policies and practices.

- University leaders are also beginning to catalyze critical work on culture and behavioral change to realign incentives in research institutions and funders to properly incentivize and support it as a priority.

- And as the threat of COVID-19 emerged, one of the very first things that Science and Health Ministers from around the world did was to call for the immediate establishment of an Open Access database of all coronavirus papers. The Open Access article database has been heavily used for text and data mining and other AI-driven and computations uses, has been accessed more than 160 million times since it was established in March of 2020[13].

These are all breathtaking milestones. We have come so far; and yet that last example is also a striking reminder of how far we have yet to go. We should not have to wait for an emergency such as an emerging pandemic to motivate us to break the glass and frantically liberate papers to create a limited collection of Open Access papers. We are long past the time where open availability and full computational use should be the norm for scientific and scholarly articles.

\section{The future of $\mathrm{OA}$ - next steps}

When we reflect on our progress, there are still majors places where we have not yet succeeded in making meaningful progress. It is not only that we haven't met the full goal of providing everyone, everywhere immediate and unfettered access to knowledge. If we are going to truly treat knowledge-sharing as a human right and optimize a system so that everyone can benefit, we need strategies/solutions that also ensure that everyone, everywhere has the same ability to contribute to the global knowledge base.

If I could turn back the clock and change one thing about the Open Access movement, I'd change its name. "Access" implies that all the movement is designed to do is facilitate the ability for people to be able to get to and read articles when the end goal is so much more than that.

"The golden thread is the need for unhindered, multidirectional participation in knowledge production and dissemination..."

- Jaya Raju, 12/4/2019 [14]

The Budapest Declaration underscored that the end goal was to empower individuals and communities around the world with the ability to share their knowledge as well as to share in accessing the knowledge of others. We must look critically at who currently can participate in the production of knowledge, and whose voices are represented the "global intellectual conversation" we want to facilitate. Whose voices are still are left out because structural barriers - be they technical, financial, legal, cultural, or linguistic prevent them from joining?

The Open Access community has been working hard to center these questions in its work over the past several years, working on the critical need to address issues of increasing participation and equity. Analyses of the current author base of scholarly journal articles shows us clearly that we have a problem. Juan Pablo Alperin and colleagues at the Scholarly Communications Lab (ScholComm Lab) at Simon Fraser University have created this visual of a map of world scaled by the number of articles currently published by authors from each country. Using data about publications by country sourced from Scopus and data on population and GDP sourced from the World Bank, you can see the stark differences in geographic representation. These differences are present not only in developed vs. less developed 
countries, but also internally on national levels where institutional disparities abound. This is illustrative of massive issues of under-inclusion not only in the scientific communications process, but also in the conduct of research itself.

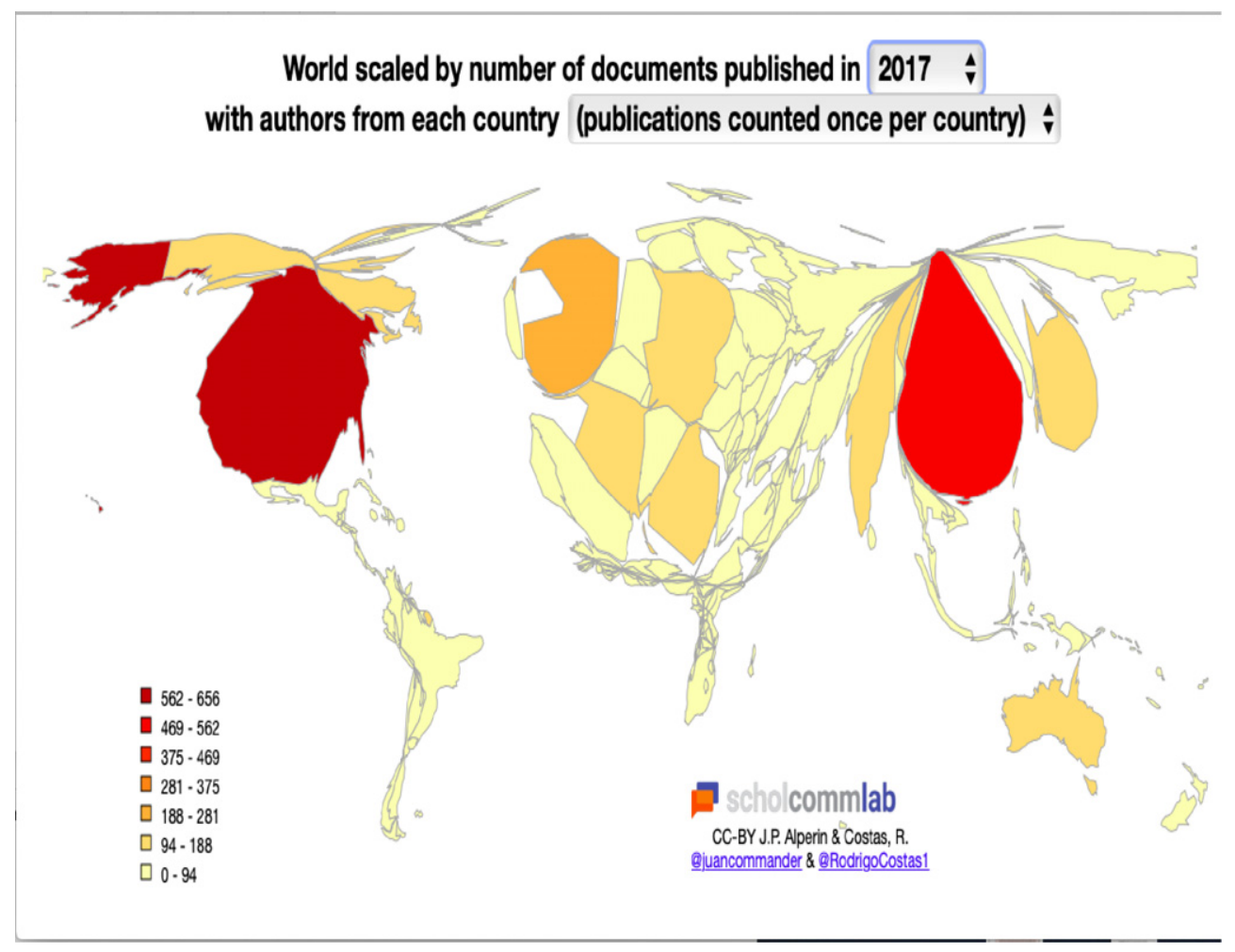

Recently, Sudip Parikh, the CEO of the American Association for the Advancement of Science, (AAAS) noted the pressing need for more deliberate inclusion in science on a systems level in an essay in the journal Science and called out the all-too common reasons behind the reluctance of many to recognize and address this pressing issue:

"Insisting on inclusion of underrepresented groups neither sacrifices scientific excellence nor diminishes the accomplishments of those who have historically dominated the sciences. Highlighting the previously ignored does not invalidate the already admired... [15]"

The biggest challenge facing the Open Access movement today is the need to press for strategies and solutions that directly address this underrepresentation, and that do not simply reinforce existing inequities by moving the same pieces to different locations on the game board.

Whatever our role in the research and education ecosystem, each one of us is faced with making choices in our daily work that can have an impact on this - either positive or negative. This requires a significant change in our mindset, where we have a responsibility to think deliberately about all our decisions through the lens of our respective - and collective - missions and values. We need to carefully and deliberately center inclusion equity implications (whose interests are served, whose might be left out?) when we are deciding: 
- The business models that we support.

- The technology that we build or buy.

- The rights with which we empower users and producers.

- The outputs and behaviors that we incentivize and reward.

- The construction of our leadership/governance bodies.

This type of systems-level change can only be made through a series of deliberate, consistent choices. Recognizing that equity must be deliberately and to proactively built into the knowledge sharing system at all possible critical choice points, and not be left to be bolted on later as an afterthought in order to have a system that is both open by default and equitable by design - for everyone.

We've seen from experience what happens when we don't make this a priority. When we catch ourselves saying things like "we'll just start by doing this for now and figure out how to solve the equity issues later," we're just fooling ourselves. Once a decision is made, we lose leverage and inequities become entrenched We've spent decades trying to unpack and undo the fundamental power imbalances in our knowledge sharing system and we cannot afford to repeat the same mistakes by treating issues of equity in ensuring that knowledge-sharing is a human right an afterthought.

This inextricable link between access to knowledge and the fulfillment of basic human rights serves as crucial reminder of the imperative for each of us think critically, and to act deliberately - individually and together.

I only wish I had two lifetimes to collaborate with you all towards making this vision a reality.

\section{About the author}

Heather Joseph has served as the Executive Director of the Scholarly Publishing and Academic Resources Coalition (SPARC) since 2005. In that capacity, she works to support broadening access to the results of scholarly research through enabling open access publishing, archiving and policies on a local, national, and international level.

Ms. Joseph is also the convener of the Alliance for Taxpayer Access, a coalition of universities, libraries, patient advocacy groups, consumer groups, and student organizations who work to ensure that results of publicly-funded research are openly accessible to the public. The group has been a leading voice on U.S. Open Access policies, including the landmark public access policy issued by the National Institutes of Health (NIH), and the recent White House Directive mandating public access to publicly funded research across all U.S. science agencies.

Prior to coming to SPARC, she spent fifteen years as a publisher in both commercial and not-for-profit publishing organizations. She served as the publishing director at the American Society for Cell Biology, which became the first journal to commit its full content to the NIH's pioneering open repository, PubMed Central, and subsequently served on the National Advisory Committee for the project.

Ms. Joseph serves on the Board of Directors of numerous not-for-profit organizations, including the Public Library of Science. She is a frequent speaker and writer on scholarly communications in general, and on open access in particular. E-mail: heather@sparcopen.org.

\section{References}

[1] https://www.un.org/en/about-us/universal-declaration-of-human-rights, accessed September 4, 2021.

[2] https://sdgs.un.org/goals, accessed September 4, 2021. 
[3] https://en.wikipedia.org/wiki/LaTex, accessed September 4, 2021.

[4] https://en.wikipedia.org/wiki/tex, accessed September 4, 2021.

[5] https://profiles.nlm.nih.gov/spotlight/mv/catalog/nlm:nlmuid-101584926X356-doc, accessed September 9, 2021.

[6] A.S. Relman, The NIH E-biomed proposal - a potential threat to the evaluation and orderly dissemination of new clinical studies, New England Journal of Medicine 340(23) (1999), 1828-1829.

[7] https://www.budapestopenaccessinitiative.org, accessed September 4, 2021.

[8] https://www.budapestopenaccessinitiative.org/read, accessed September 4, 2021.

[9] https://www.budapestopenaccessinitiative.org/read, accessed September 4, 2021.

[10] https://www.stm-assoc.org/2018_10_04_STM_Report_2018.pdf, accessed September 4, 2021.

[11] https://en.unesco.org/science-sustainable-future/open-science/recommendation, accessed September 4, 2021.

[12] https://www.coalition-s.org, accessed September 4, 2021.

[13] https://sparcopen.org/news/2020/strong-community-response-to-free-scholarly-article-access-to-fight-covid-19, accessed September 4, 2021.

[14] Speaker at the UCT-SPARC Africa Open Access Symposium, December 2-6, 2019. See: www.sparcafricasymp.uct.ac.za, access September 4, 2021.

[15] https://science.sciencemag.org/content/371/6528/443, accessed September 4, 2021. 